Proceedings

\title{
Better Effect of a Lower Dose of Plant Substances in Deterring Storage Pests ${ }^{\dagger}$
}

\author{
Aleksandra Izdebska ${ }^{1, *}$, Małgorzata Kłyś' ${ }^{1}$, Sylwia Koczanowicz ${ }^{2}$ and Magdalena Nowak-Chmura ${ }^{2}$ \\ 1 1Institute of Biology, Department of Ecology and Environmental Protection, Pedagogical University of Cra- \\ cow, Podchorążych 2, 30-084 Kraków, Poland; malgorzata.klys@up.krakow.pl \\ 2 Institute of Biology, Department of Zoology, Pedagogical University of Cracow, Podchorążych 2, 30-084 \\ Kraków, Poland, sylwia.koczanowicz@student.up.krakow.pl; magdalena.nowak-chmura@up.krakow.pl \\ * Correspondence: aleksandra.izdebska2@student.up.krakow.pl \\ + Presented at the 1st International Electronic Conference on Entomology (IECE 2021), 1-15 July 2021; \\ Available online: https://iece.sciforum.net/.
}

Citation: Izdebska, A.; Kłyś M.;

Koczanowicz S.; Nowak-Chmura, M. Better Effect of a Lower Dose of Plant Substances in Deterring Storage Pests, in Proceedings of the 1st International Electronic Conference on Entomology, 1-15 July 2021, MDPI: Basel, Switzerland, doi:10.3390/IECE-10401

Published: 30 June 2021

Publisher's Note: MDPI stays neutral with regard to jurisdictional claims in published maps and institutional affiliations.

Copyright: (c) 2021 by the authors. Submitted for possible open access publication under the terms and conditions of the Creative Commons Attribution (CC BY) license (http://creativecommons.org/licenses /by/4.0/).

\begin{abstract}
The aim of the study was to compare the effect of two concentrations ( 0.1 and $1 \%)$ of different plant substances on dettering Rhyzopertha dominica F. and Sitophilus granarius L. Both species were treated with the essential oils of Foeniculum vulgare Mill. and Carum carvi L. as well as L-carvone and anethole. The tests were carried in laboratory. The deterrence of insects were noted after 1, 2, 3, 4, 5, 24 and $48 \mathrm{~h}$. It turned out that the essential oils and chemical compounds used in the experiments do not show the normal relationship described in the previous literature on storage pests, in which the repellency gets higher with the increase in the concentration of the tested plant material. It was found that a lower dose of the tested substances causes a greater deterrence of these species of beetles. In the case of $R$. dominica, the highest repellant effect was exerted by the concentration of $0.1 \%$ L-carvone. Differences between the concentration of $0.1 \%$ and $1 \%$ were found among all tested substances in each time interval in the deterrent of $R$. dominica. This difference ranged from $4.17 \%$ to $52.92 \%$. All substances used in the tests had a large deterrent effect on $S$. granarius (from 48 to 100\%). Differences in the deterrence of S. granarius were found between $0.1 \%$ and $1 \%$ concentration in most of the tested substances in each time interval. The difference ranged from $1 \%$ to $15.42 \%$.
\end{abstract}

Keywords: plant substances; repellence; storage pests

\section{Intoduction}

Rhyzopertha dominica F. (Coleoptera, Bostrichidae), the lesser grain borer and Sitophilus granarius L. (Coleoptera, Dryophthoridae), grain weevil are one of the most dangerous species of primary pests that destroy grains [1, 2, 3, 4, 5, 6]. These pests are widely distributed all over the world. In the tropical and subtropical climate zone, they cause damage to crops as well as to stored grains and their milling products. In countries with a moderate climate among others in Poland their development is limited mainly to heated warehouses where they destroy the accumulated food stocks $[7,8,9]$.

By causing economic and health losses, storage pests have for years been motivating scientists and food producers to undertake various methods of their elimination. Currently used pest control methods are not effective in one hundred percent and neutral to human health and the environment. Among other, these factors contributed to the intensification of research new, effective methods of pest control. Scientists are still looking for effective, safe for humans and the environment, yet cost-effective and readily available ways to reduce pests. It seems that these conditions are met by substances of plant origin, because they more readily biodegrade, pollute the environment less frequently and are less toxic to mammals [10,11, 12, 13]. 
The aim of the presented research was to compare the effect of two concentrations of different plant substances on the deterrence of $R$. dominica and $S$. granarius. Both species were treated with the essential oils of Foeniculum vulgare Mill. and Carum carvi L. as well as L-carvone and anethole.

\section{Methods}

The tests were carried out in the laboratory at the temperature of $29^{\circ} \pm 1^{\circ} \mathrm{C}$ and $60 \pm 5 \%$ RH. Adult R. dominica and S. granarius individuals were used in the tests. The research used the emigration (repellence) methodology developed by Kłyś (2007) [14]. The experimental vessels consisted of two plastic containers - the inner one with a base area of $28 \mathrm{~cm}^{2}$ and the outer one with a base area of $50 \mathrm{~cm}^{2} .40 \mathrm{~g}$ of wheat was added to each container. The inner container had 30 holes in the base bottom area and side walls $1.5 \mathrm{~mm}$ in diameter. Four $4 \mathrm{~cm}$ screws are fitted to the bottom of the inner container. This prevented the beetles from returning to the inner container. The insects were placed in an inner container and a disc of filter paper. It was soaked with the essential oils of Foeniculum vulgare, Carum carvi, L-carvone and anethole in concentrations of 0.1 and 1\% (w/v). 40 beetles were added to the inner container. Insect repellent was recorded after 1, 2, 3, 4, 5, 24 and 48 hours of exposure. Each variant of the experiment was carried out in six replications. The emigration (repellency) index was calculated by dividing the sum of the average number of living and dead emigrants by the average number of living and dead individuals in both containers. The result was multiplied by $100 \%$ to obtain the percentage of repellency [15].

The control culture was performed under the same conditions and in the same set of containers as the research samples. The substrate in the control culture was $40 \mathrm{~g}$ of pure wheat into which 40 beetles were released.

The ANOVA Kruskall-Wallis rank test was applied, followed by a multiple comparison test. The test probability level " $p$ " and the significance level " $\alpha$ " were 0.05 . The calculations were performed in the Statistica 13.3 program.

\section{Results}

All substances used in the tests in each time interval caused deterrence $S$. granarius and $R$. dominica. Only $1 \%$ of fennel essential oil after 1 hour of research did not cause emigration of $R$. dominica. The highest emigration (repellency) of $R$. dominica, confirmed by the highest values of the emigration index ranging from 40 to $90 \%$, was caused by $0.1 \%$ L-carvone in all tested time intervals. Anethole caused the lowest emigration. On the other hand, in the control culture, the values of the emigration index were low throughout the study period, ranging from 7 to $29 \%$ (Figure 1, Figure 2 and Figure 3).

Also, all plant substances used in the tests resulted in large emigration of $S$. granarius in all time intervals. The highest emigration (deterrence) was obtained after the use of $0.1 \%$ fennel essential oil, then $1 \%$ L-carvone in all time intervals and $0.1 \%$ caraway essential oil from 2 to 48 hours. Already after 2 hours of research, the emigration of $S$. granarius was over 60\%, and after 24 and 48 hours it was from 90 to $100 \%$. While in the control culture it was relatively low and ranged from 4 to 38\% (Figure 1, Figure 2 and Figure 4).

It was found that the lower concentration $0.1 \%$ of the applied plant substances caused a greater effect in repelling the lesser grain borers and grain weevils. This relationship was not found only for the effect of anethole on $R$. dominica (Figure 3).

Although not all differences are statistically significant, there is a clear tendency lower concentration - higher emigration (repellency) of both species. Much greater differences in the repelling of beetles between the concentrations of $0.1 \%$ and $1 \%$ of the plant material used were noted for the lesser grain borers than the grain weevils. For the $R$. dominica, the biggest difference was recorded for caraway essential oil after 48 hours, it was $52.92 \%$. However, for S. granarius the differences were smaller, because in most of the 
results they did not exceed $10 \%$, the highest was recorded for L-carvone $5.42 \%$ after $1 \mathrm{~h}$ of research. On the other hand, all the substances used caused a much greater deterrent of $S$. granarius (Figure 2 and Figure 4).

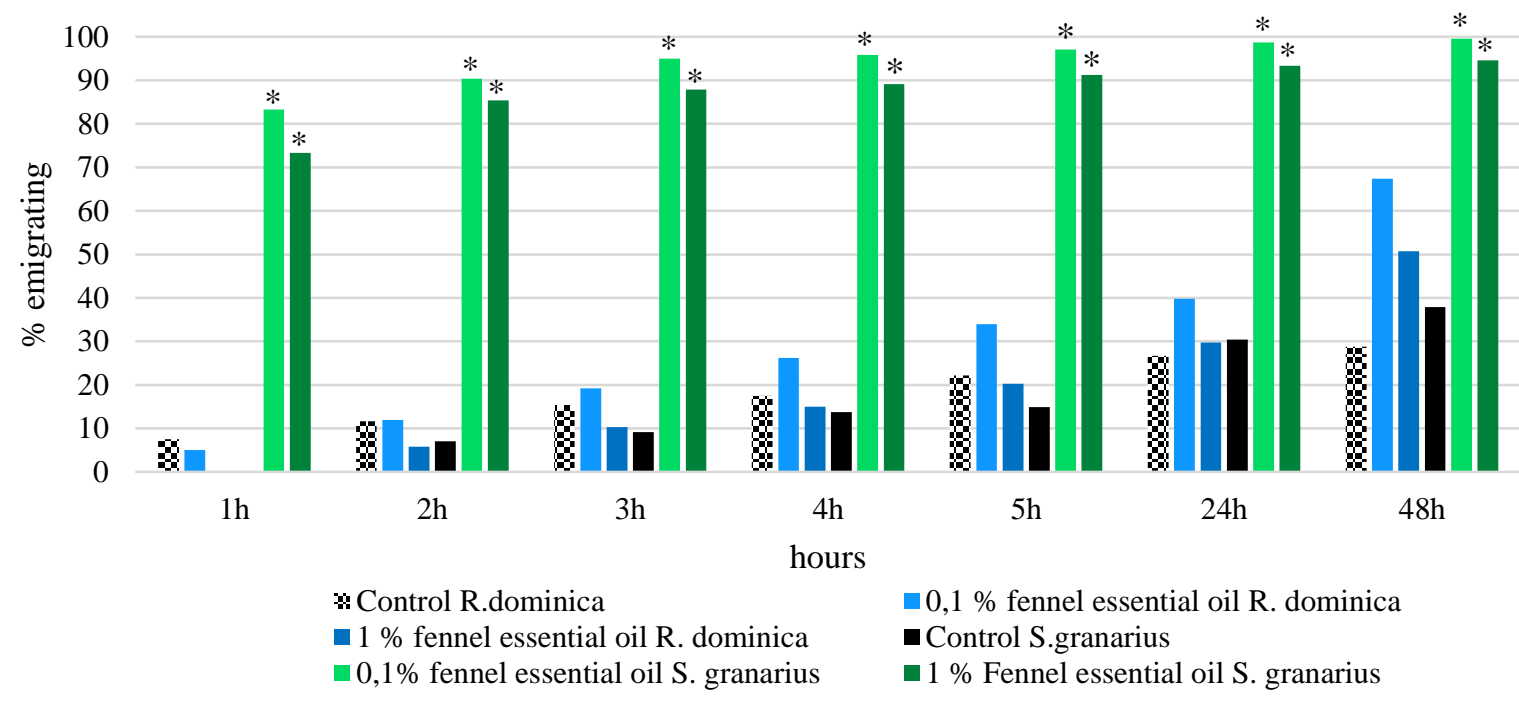

Figure 1. Repellency of S. oryzae and R. dominica caused by fennel essential oil (Statistically significant differences are marked with an asterisk).

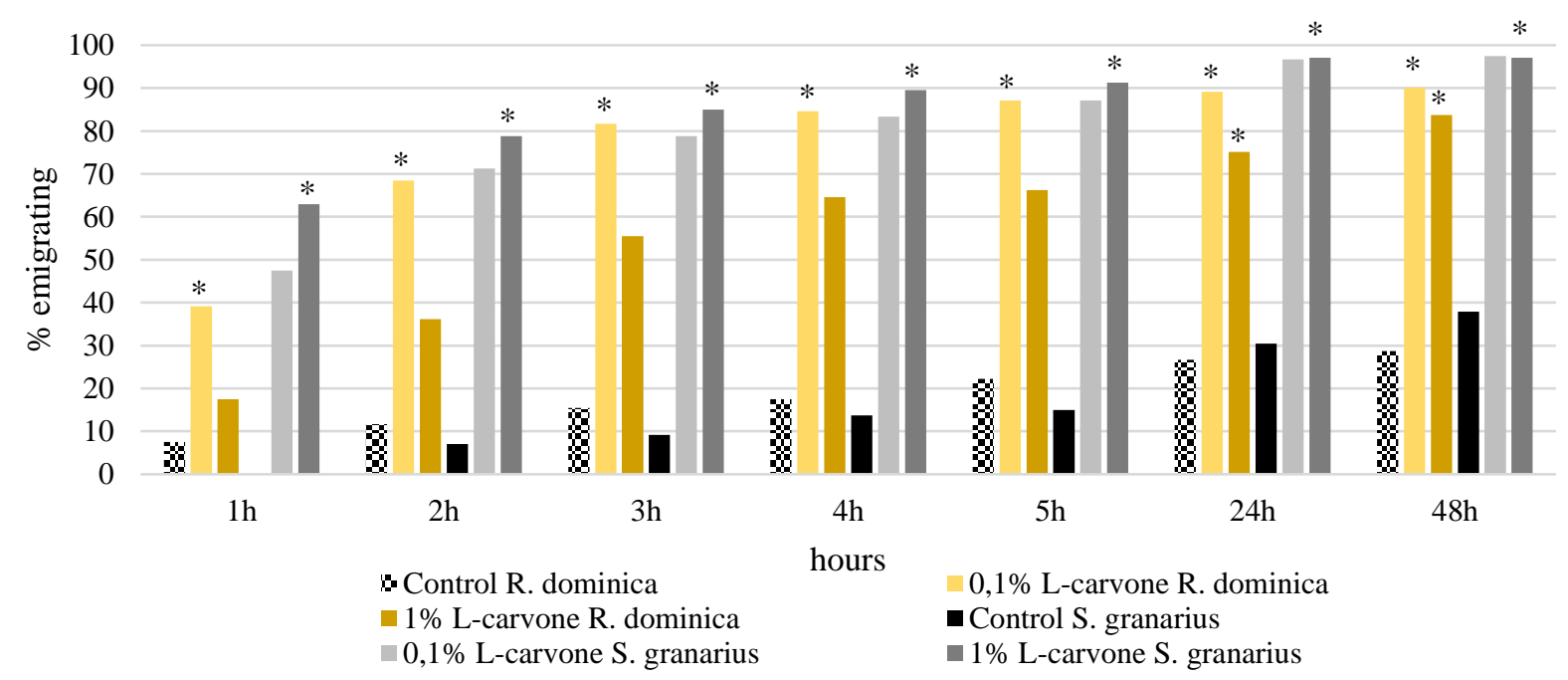

Figure 2. Repellency of S. oryzae and R. dominica caused by L-carvone (Statistically significant differences are marked with an asterisk). 


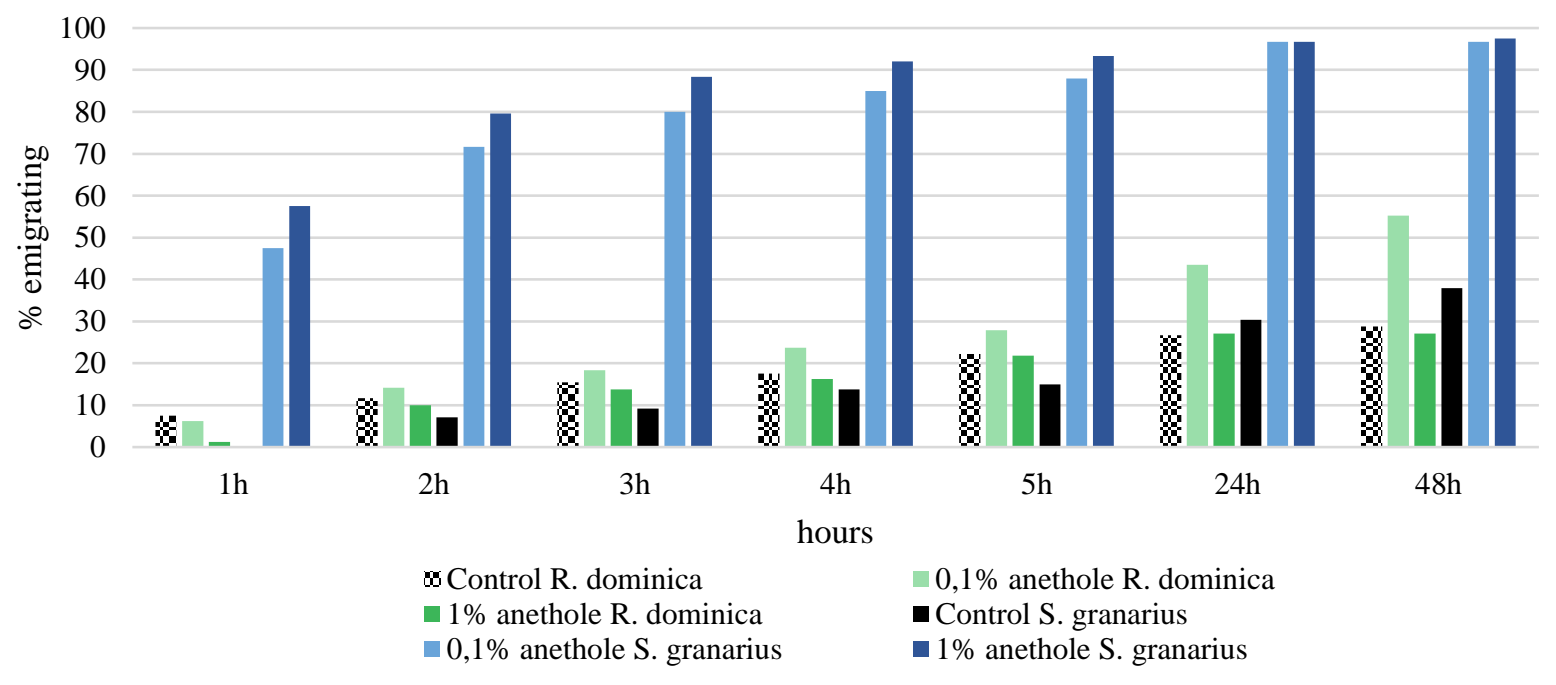

Figure 3. Repellency of S. oryzae and R. dominica caused anethole.

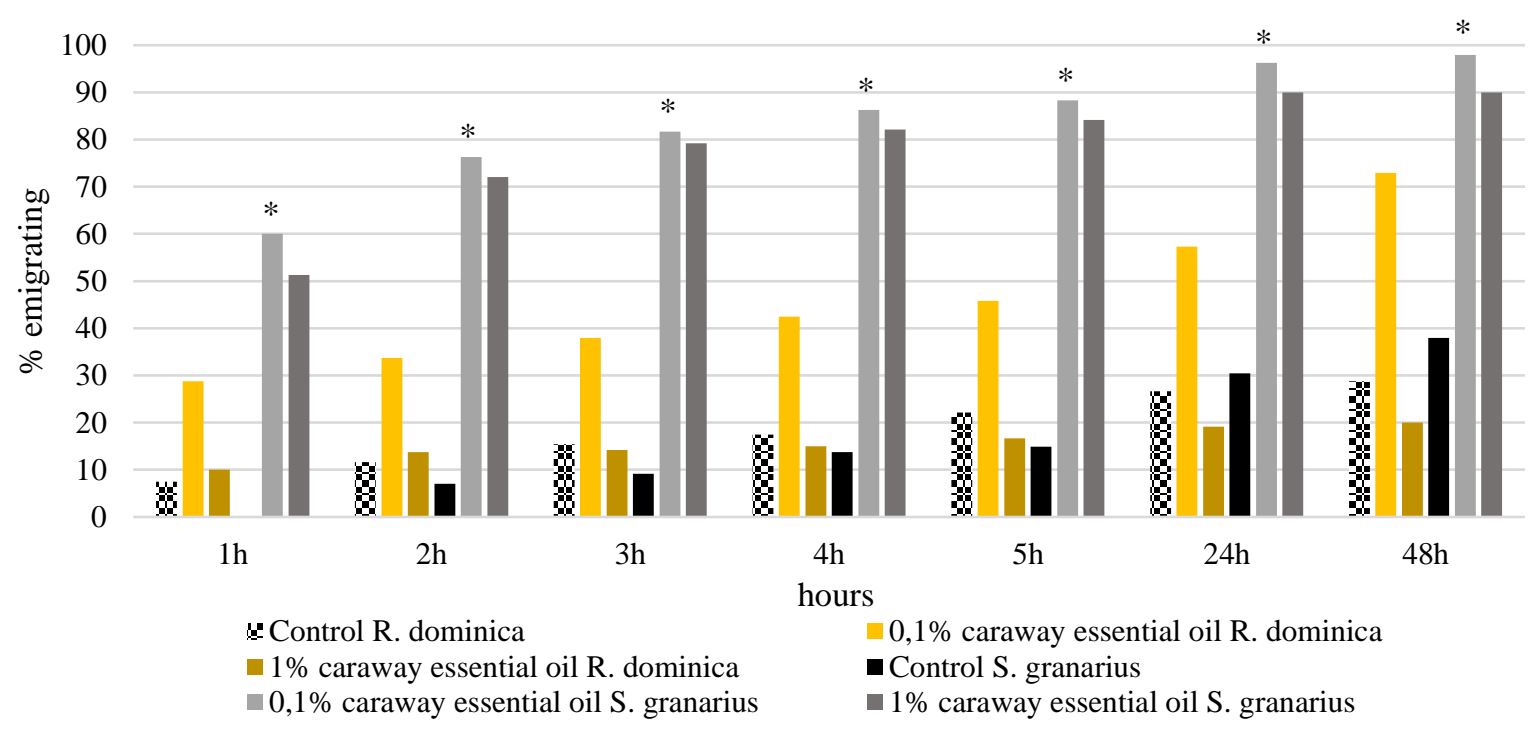

Figure 4. Repellency of S. oryzae and R. dominica caused by caraway essential oil (Statistically significant differences are marked with an asterisk).

\section{Discussion}

Plant substances meet the assumptions of the current method of safe pest reduction, which is integrated control [16, 17]. In addition, it is important that the plants used and the essential oils contained in them, as well as chemical compounds, apart from the repellant and/or insecticidal effect on pests, are safe for humans and do not adversely affect the stored food products. Therefore, in the presented research, spice plants were used, with healing and bactericidal properties, showing properties that repel storage pests.

In this study, a high deterrent effect against $S$. granarius caused all plant substances used in the tests, especially fennel oil (73-100\%) and caraway oil (51-98\%) in both concentrations and throughout the entire period of the study. The highest deterrent effect of $R$. dominica (40-90\%) was caused by the lower $0.1 \%$ concentration of L-carvone.

Also Kłyś et al. [15] showed a high (98-99\%) deterrent effectiveness of caraway oil in concentrations of $0.1,0.5$ and 1\% after 24 hours of testing against Sitophilus oryzae. They obtained similar results with L-carvone. 
In turn, Bedini et al. [18] found the repellant potential of the substances contained in fennel. They studied two chemotypes - estragole and anethole of fennel essential oil and the chemicals they contain: anethole, estragole, limonene and phenchon. The subjects of their research were $R$. dominica, Sitophilus zeamais and Tribolium confusum. Both types of essential oils were tested at doses ranging from 0.005 to $0.385 \mathrm{mg} / \mathrm{cm}^{2}$, while the compounds were tested at various doses from 0.01 to $0.74 \mathrm{mg} / \mathrm{cm}^{2}$. Estragole essential oil and estragole turned out to be the most effective.

In assessing the possibility of using a substance of plant origin as a repellant, two parameters are important: its effectiveness and the time in which it will produce the expected effect. The effectiveness is assessed using various indicators, incl. repellency index. Equally important is the concentration of the substance used, which will produce the desired effect, as too high may be economically and health unjustified.

Many publications on the repellant effect of substances of plant origin against storage pests show the dependence of the effect on the concentration used. Usually, an increase in the deterrent effect was observed with an increase in the applied concentration of the test substance $[19,20,21,22,23]$.

The presented studies showed a stronger deterrent effect on both species of the lower tested concentration of the tested plant substances. These results correspond with the studies by Kłyś et al. [15], which using a greater number of concentrations of L-carvone $(0.05,0.1,0.5,1 \%)$ and caraway oil $(0.1,0.5,1 \%)$ against $S$. oryzae, recorded a stronger effect of lower L-carvone doses. This compound at a dose of $0.1 \%$ caused $100 \%$ beetle emigration after 24 hours. Higher concentrations of 0.5 and $1 \%$ show a much lower deterrent effect.

Also Benelli et al. [20] showed that one of the examined oils from Hyptis suaveolens caused a higher repellency of $S$. granarius at a lower concentration $0.1 \%$, not $1 \%$.

It is known that DEET is the most common active ingredient in repelling mosquitoes, ticks and other arthropods when applied to skin or clothing. The more of this compound the repellent contains, the longer it can protect against mosquito bites. Its higher concentrations provide longer protection, but the concentration of DEET above 50\% does not bring much effect $[24,25]$.

\section{Conclusion}

The lower dose of $C$. carvi and F. vulgare essential oils, as well as carvone had the greatest deterrent effect on $S$. granarius and $R$. dominica. These results differ from the results obtained so far with regard to stored pests, the repellency increased with the increase in the concentration of the applied substances.

\footnotetext{
Author Contributions: conceptualization, M.K.; methodology, M.K.; analysis of results and investigations, A.I.; writing - review and editing, M.K., A.I. and S.K.; compiled figures, A.I.; collect references, S.K. and M.N-Ch.; supervision, M.K. All authors have read and agreed to the published version of the manuscript.

Institutional Review Board Statement: Not applicable.

Funding: This research received no external funding.

Informed Consent Statement: Not applicable.

Conflicts of Interest: The authors declare no conflict of interest.
}

\section{References}

1. Eldridge, J.V. Landscape ecology of the lesser grain borer, Rhyzopertha dominica. Applied Science. Queensland, University of Technology, 2014; pp. 117.

2. Srivastava, C.; Subramanian, S. Storage insect pests and their damage symptoms: an overview. Indian Journal of Entomology 2016, 78, 53-58.

3. Germinara, G.S.; Cristofaro, A.; Rotundo, G. Behavioral Responses of Adult Sitophilus granarius to Individual Cereal Volatiles. J Chem Ecol 2008, 34, 523-529

4. Woodbury, N. Infanticide avoidance by the granary weevil, Sitophilus granarius (L.) (Coleoptera: Curculionidae): the role of harbourage markers, oviposition markers, and egg-plugs. J. insect Behav 2008, 21(2), 55-62. 
5. Holloway, J.C.; Daglish, G.J.; Mayer, D.G. Spatial Distribution and Flight Patterns of Two Grain Storage Insect Pests, Rhyzopertha dominica (Bostrichidae) and Tribolium castaneum (Tenebrionidae): Implications for Pest Management. Insects 2020, 11, 715.

6. Lemic, D.; Mikac, K.M.; Genda, M.; Jukić, Ž.; Pajač Živković, I. Durum Wheat Cultivars Express Different Level of Resistance to Granary Weevil, Sitophilus granarius (Coleoptera; Curculionidae) Infestation. Insects 2020, 11, 343.

7. Nawrot, J. Owady - szkodniki magazynowe, Publisher: THEMAR, Warszawa, 2001; pp. 3-71.

8. Rees, D. Insects of stored products, Publisher: CRISO, Australia, 2004; pp. 5-52.

9. Kłyś, M. Wpływ ziół na niektóre gatunki chrząszczy szkodliwe w magazynach i przechowalniach, Publisher: Naukowe Uniwersytetu Pedagogicznego, Kraków, 2013; pp. 76.

10. Isman, M.B. Botanical insecticides, deterrents, and repellents in modern agriculture and an increasingly regulated world. Annu Rev Entomol 2006, 51, 45-66.

11. Singh, R.; Koul, O.; Rup, P.J.; Jindal, J. Toxicity of some essential oil constituents and their binary mixtures against Chilo partellus (Lepidoptera: Pyralidae). Int J Trop Insect Sci 2009, 29, 93.

12. Regnault-Roger, C.; Vincent, C.; Arnason, J.T. Essential oils in insect control: Low-risk products in a high-stakes world. Annu Rev Entomol 2012, 57, 405-424.

13. Plata-Rueda, A.; Rolim, G.D.S.; Wilcken, C.F.; Zanuncio, J.C.; Serrão, J.E.; Martínez, L.C. Acute Toxicity and Sublethal Effects of Lemongrass Essential Oil and Their Components against the Granary Weevil, Sitophilus granarius. Insects 2020, 11, 379.

14. Kłyś, M. The influence of the herbs sage and wormwood on the migration of Rhyzopertha dominica (F.) (Coleoptera: Bostrichidae) populations. J Stored Prod Res 2007, 43, 558-563.

15. Kłyś, M.; Izdebska, A.; Malejky-Kłusek, N. Repellent Effect of the Caraway Carum carvi L. on the Rice Weevil Sitophilus oryzae L. (Coleoptera, Dryophthoridae). Insects 2020, 11(12), 836.

16. Rajashekar, Y.; Bakthavatsalam, N.; Shivanandappa, T. Botanicals as grain protectants. Psyche: A Journal of Entomology 2012, 1-13.

17. Campolo, O.; Giunti, G.; Russo, A.; Palmeri, V.; Zappal, L. Essential Oils in Stored Product Insect Pest Control. Journal of Food Quality 2018, 4, 1-18.

18. Bedini, S.; Bougherra, H.H.; Flamini, G.; Cosci, F.; Belhamel, K.; Ascrizzi, R.; Conti, B.. Repellency of anethole- and estragoletype fennel essential oils against stored grain pests: the different twins. Bulletin of Insectology 2016, 69(1), 149-157.

19. Ko, K.; Juntarajumnong, W.; Chandrapatya, A. Repellency, fumigant and contact Toxicities of Litsea cubeba (Lour.) persoon against Sitophilus zeamais Motschulsky and Tribolium castaneum (Herbst). Kasetsart J Nat Sci 2009, 43, 56-63.

20. Lashgari, A.; Mashayekhi, S.; Javadzadeh, M.; Marzban, R. Effect of Mentha piperita and Cuminum cyminum essential oil on Tribolium castaneum and Sitophilus oryzae. Archives of Phytopathology and Plant Protection 2014, 47(3), $324-329$.

21. Waliullah,T.M.; Yeasmin, A.M.; Wahedul, I.M.; Parvez, H. Mortality and repellent activity of Clerodendrum Viscosum Vent. (Verbenaceae) against Sitophilus oryzae (Coleoptera: Curculionidae). Int J Pharmacogn 2014, 1, 250-257.

22. Kachhwaha, N.; Meena, G.D.; Meena S. Plant extracts controls Oryzaephilus surinamensis by showing repellency behavior. Eur J Exp Biol 2015, 5, 98-101.

23. Benelli, G.; Flamini, G.; Canale, A.; Molffetta, I.; Cioni, P.L.; Conti, B. Repellence of Hyptis suaveolens whole essential oil and major constituents against adults of the granary weevil Sitophilus granarius. Bull Insect 2012, 65, 177-183.

24. Nasci, R. S.; Zielinski-Gutierrez, E.; Wirtz, R. A.; Brogdon, W. G, Protection against mosquitoes, ticks, other insects and arthropods, Publisher: Oxford University Press, New York, 2014; pp. 26-487

25. Kozarsky, P.; Keystone, J.S.; Freedman, D.O.; Nothdurft, H.D.; Connor, B. A. Travel Medicine E-Book: Expert Consult. Elsevier Health Sciences 2008. 